\title{
INFLUENCING FACTORS OF THE DIABETES DISTRESS AMONG CHINESE PATIENTS WITH TYPE 2 DIABETES MELLITUS
}

\author{
Huilan Bao, Junru Liu \& Jun Ye \\ The Endocrinology Department of the People's Hospital of Jinhua, Jinhua, China
}

received: 15.5.2018;

revised: 1.8.2018;

accepted: 8.8.2018

\begin{abstract}
SUMMARY
Background: Patients with Diabetes Mellitus (DM) are required to have long-term treatment regimen and strict selfmanagement, which thus might lead to the Diabetes Distress (DD). Patients' DD varies in different regions with different levels of medical conditions. For improving the treatment effect of the patients with the Type-2-Diabetes-Mellitus (T2DM), this study explores the influencing factors of the patients' $D D$ in the regions where the medical treatment are at low level.

Subjects and methods: In this study, 167 adult patients with T2DM were selected from the People's Hospital of Jinhua city, an A-grade hospital of a small-mid-sized city in Eastern China. Based on these samples, the Diabetes Distress Scale with 17 items (DDS17) was adopted to measure the degree of patients' DD, and then regression analyses were carried out to investigate the influencing factors for their $D D$.

Results: The T2DM patients with moderate and high levels of DD take up $54.5 \%$ of the samples investigated in this study. According to the Spearman correlation analysis, sleep time, physical exercise, diet control, treatment regimen, TG and HbAlc significantly affect the patients' $D D$. Through the multivariate linear regression analysis, this study shows that (1) sleep time significantly influences the T2DM patients' $D D(\beta=-0.213, P=0.034)$; (2) sleep time also impacts emotional burden $(\beta=-0.379$, $P=0.027)$; (3) physical exercise $(\beta=-0.195, P=0.002)$, treatment regimen $(\beta=0.158, P=0.026)$ and diet control $(\beta=0.158, P=0.026)$ are the three major influencing factors for regimen-related distress.

Conclusion: In the small-mid-sized city where the treatment regimen is not highly advanced, to alleviate the T2DM patients' DD, the medical staff should suggest the patients to improve sleep quality and exercise more, help them positively understand the insulin infusion therapy and take proper diet control.
\end{abstract}

Key words: T2DM - Diabetes Distress - influencing factors

$* * * * *$

\section{INTRODUCTION}

T2DM is a lifelong chronic disease with high-morbidity. Patients with T2DM require long-term treatment regimen and strict self-management to ameliorate the blood glucose, slow down the disease progression, and prevent the possible complications. However, due to the poor therapeutic effect, expensive treatment regimen, frequent complications and long-term self-management, the patients could easily suffer severe mental stresses and emotional burdens, which thus eventually hampering them from self-management. Snoek et al. (2011) found that $25.0 \%$ of the patients with DM suffered depression in different degrees. Li et al. (2008) suggested that $20 \%$ of the American adults with DM had symptoms of anxiety, and $33 \%$ of them suffered severe depression. Furthermore, De Vries et al. (2014) showed that DD not only brought about emotional burden, but also hampered the patients' confidence in self-management and treatment regimen, thus led to blood glucose disorders and low life qualities. However, if the medical staff could help the patients relieve DD, then the effect of treatment regimen on DM could be greatly improved.

It has been proved that the high-level treatment regimen could significantly alleviate the T2DM patients' DD (Reddy et al. 2013). However, what are the major influencing factors for the patients' DD in the smallmid-sized cities (e.g., Jinhua city in eastern China) where the medical conditions and treatment regimen are at low-level? To address the problem, 167 T2DM patients were selected from the People's Hospital of Jinhua (an A-grade hospital in Jinhua). This study measured these patients' DD with the DDS17 proposed by Polonsky et al. (2005). Based on this investigation, the influencing factors for the T2DM patients' DD were empirically studied through the Spearman correlation analysis and the multivariate linear regression analysis.

In the recent decades, voluminous studies, have employed two sets of scales (i.e., the Problem Areas In Diabetes scales (PAID) (Polonsky et al. 1995) and the DDS (Polonsky et al. 2005)) to investigate the influencing factors for the patients' DD, including gender, marital status, social support, and medical conditions. These studies could be categorized into four streams as follows.

The first stream focuses on the impacts of the patients' medical course, gender and personal health condition on their DD. For example, Kasteleyn et al. (2015) discovered that the longer the course of DM was, the more likely it was for the patients to have complications and to resort to intensive insulin therapy. Therefore, the patients' medical course would significantly increase their burdens of self-management and the degree of DD. Baek et al. (2014) studied 119 subjects with T2DM, and found that complications positively correlated with the patients' DD in self-management burden. However, 
Ikeda et al. (2014), after investigating 216 T2DM patients in Japan and USA, came to an opposite conclusion that the patients without diabetic complications were more likely to suffer DD because of fearing the possible future complications. Graue et al. (2014) investigated 411 T2DM patients in Norway, and found that the females were more likely to suffer DD than the males. What was more, they discovered that the patients' DD scores negatively correlated with age, which meant that the young patients suffered a higher level of DD than the older ones. Karlsen et al. (2012) and Wardian \& Sun (2014) found that there was a significant postive correlation between the body mass index (BMI) and the patients' DDS scores, which meant that the patients could greatly alleviate their DD by losing their weights.

The second stream focuses on the impacts of the diabetes-related biochemical indicators on the patients' DD. For example, Strandberg et al. (2015) found that the higher level of HbAlc the patients had, the higher the degree of DD they might suffer. Particularly, the $\mathrm{HbAlc}$ indicator had a strong positive correlation with regimen-related distress. Hessler et al. (2014) found that the patients' blood glucose level positively correlated with their DD degree. They showed that if the patients could well control the blood glucose level, then they could significantly raise their confidence in self-management, and thus obviously contributing to alleviating their DD.

The third stream focuses on the impacts of the treatment regimen on the T2DM patients' DD. For example, Delahanty et al. (2007) and Jones et al. (2016) found that the intensive insulin therapies would worsen DD of the patients, as they would assume their health conditions to be rather bad when they were suggested the insulin therapies. Such kind of the negative selfsuggestion made the patients suffer higher degree of the DD. However, we found that the researches in this stream were rather scant.

The fourth stream focuses on the impacts of social support and self-management on the T2DM patients' DD. For example, Karlsen et al. (2012), Baek et al. (2014) and De Vries et al. (2014) found that supports from the medical staff, family members and the peers could effectively alleviate the patients' DD. Likewise, the negative supports (e.g., scolding and sarcasm) would discourage the patients and thus increasing their DD (Thorne \& Paterson 2001). Therefore, Karlsen et al. (2012) suggested that, in order to alleviate the T2DM patients' DD, the doctors should encourage them to take the positive self-management and help them to restrain the negative emotions at the meantime. Wagner \& Tennen (2007) and Reddy et al. (2013) found that the T2DM patients who had suffered depression before were more likely to have DD. Nouwen (2015) further complemented the findings of Wagner \& Tennen (2007) and Reddy et al. (2013): the T2DM patients' DD would increase as long as they had symptoms and histories of depression.
Most T2DM patients investigated in the published literatures as mentioned were from the developed countries (e.g., Japan, the United States, Norway, etc.) where the medical conditions and treatment regimens were highly advanced. However, will the influencing factors be different for the T2DM patients in the regions with low-level medical conditions and treatment regimens? The studies mentioned above had highly emphasized on the impact of treatment regimens and diet controls on the T2DM patients' DD. However, it is still worthy of further study on the question: whether the living habits (e.g., the sleep time and physical exercise) would exert significant impacts on the patients' DD? In this study, we will bridge the gap of these two questions by focusing on both of the questions. 167 adult T2DM patients were selected from the People's Hospital of Jinhua (an A-grade hospital of a small-midsized city in eastern China) where the medical conditions and treatment regimens for DM are not highly advanced. Based on these samples, we explore the influencing factors that could significantly affect the T2DM patients' DD.

\section{SUBJECTS AND METHODS}

\section{Data Source and Description}

182 adult T2DM patients were selected from the endocrinology department of Jinhua People's Hospital. These samples were collected from January 2017 to December 2017. All T2DM patients selected were well informed of the objective and purpose of this study. For ensuring the patients could well understand the measures in our study, we excluded the samples with diabetic complications, mental diseases and other serious diseases (e.g., cancer). Finally, 167 samples were valid for this study, which indicating a valid rate of $91.8 \%$.

In these valid samples, there were 65 male patients and 102 female patients with the ages varied from 18 to 78 years old, registering an average age of $(52.27 \pm 14.55)$. Among all samples, the diabetic courses varied from 1 to 32 years, registering an average $(8.93 \pm 2.52)$ years. Other statistical description of the indicators were: weight $(62.53 \pm 18.27) \mathrm{kg}$, BMI $(25.29 \pm 5.03) \mathrm{kg} / \mathrm{m}^{2}$, HbAlc $(10.12 \pm 3.75) \%$, SBP $(125.88 \pm 17.31) \mathrm{mmHg}$, DBP (83.58 \pm 6.74$) \mathrm{mmHg}$, TG $(2.54 \pm 1.56) \mathrm{mmol} / \mathrm{L}$, TC $(2.47 \pm 1.65) \mathrm{mmol} / \mathrm{L}, \quad$ LDL-C $(2.86 \pm 1.63) \mathrm{mmol} / \mathrm{L}$, HDL-C $(1.19 \pm 0.83) \mathrm{mmol} / \mathrm{L}$. The statistical descriptions of these valid samples were given in Table 1.

\section{Research Methods}

First, the Spearman correlation analysis was employed to examine the correlation between the single influencing factor and DD for the T2DM patients. By doing so, the significance of single influencing factor on the patients' DD could be statistically identified. Second, the stepwise multiple regression analysis was adopted to study the influencing factors and examine how different combinations of influencing factors would affect the patients' DD. In this study, the SPSS 24.0 was utilized for all statistic and regression analyses. 
Table 1. Statistical description of the valid samples ( $M=$ Mean, $S D=$ Standard Deviation)

\begin{tabular}{lccccc}
\hline Variable & \multicolumn{2}{c}{ Total Sample $(\mathrm{N}=167)$} & Variable & \multicolumn{2}{c}{ Total Sample $(\mathrm{N}=167)$} \\
\hline Age & $52.27(\mathrm{M})$ & $14.55(\mathrm{SD})$ & $\mathrm{SBP}(\mathrm{mmHg})$ & $125.88(\mathrm{M})$ & $17.31(\mathrm{SD})$ \\
Gender & $65(\mathrm{Male})$ & $102(\mathrm{Female})$ & $\mathrm{DBP}(\mathrm{mmHg})$ & $83.58(\mathrm{M})$ & $6.74(\mathrm{SD})$ \\
Course $($ year$)$ & $8.93(\mathrm{M})$ & $2.52(\mathrm{SD})$ & $\mathrm{TG}(\mathrm{mmol} / \mathrm{L})$ & $2.54(\mathrm{M})$ & $1.56(\mathrm{SD})$ \\
Weight $(\mathrm{kg})$ & $62.53(\mathrm{M})$ & $18.27(\mathrm{SD})$ & TC $(\mathrm{mmol} / \mathrm{L})$ & $2.47(\mathrm{M})$ & $1.65(\mathrm{SD})$ \\
BMI $\left(\mathrm{kg} / \mathrm{m}^{2}\right)$ & $25.29(\mathrm{M})$ & $5.03(\mathrm{SD})$ & LDL-C $(\mathrm{mmol} / \mathrm{L})$ & $2.86(\mathrm{M})$ & $1.63(\mathrm{SD})$ \\
HbA1c $(\%)$ & $10.12(\mathrm{M})$ & $3.75(\mathrm{SD})$ & HDL-C $(\mathrm{mmol} / \mathrm{L})$ & $1.19(\mathrm{M})$ & $0.83(\mathrm{SD})$ \\
\hline
\end{tabular}

Table 2. Statistical descriptions of the personal information and DD scores $[\mathrm{n}(\%), \bar{x} \pm \mathrm{s}]$

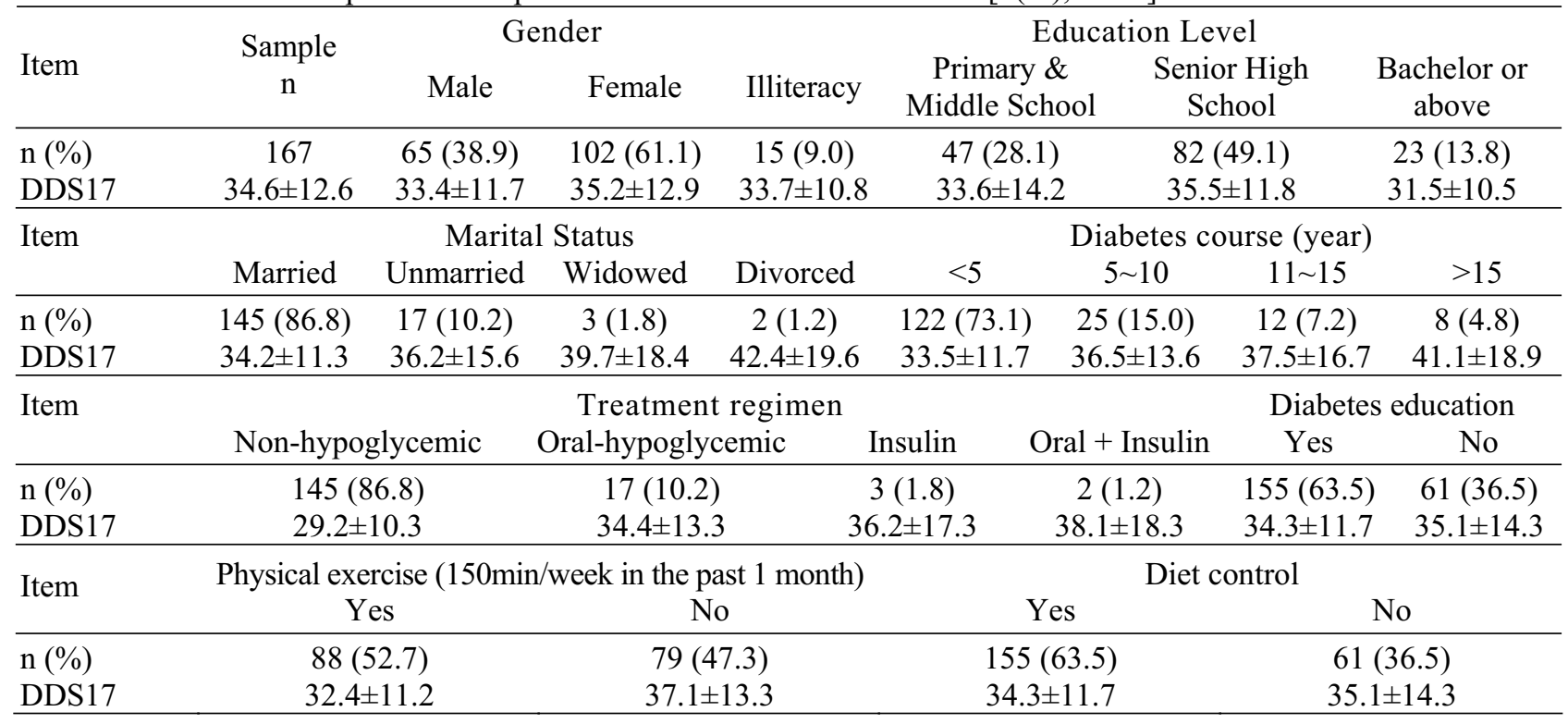

Table 3. Statistical description on DD in different subscales $[\bar{x} \pm \mathrm{s}, \mathrm{n}(\%)]$

\begin{tabular}{lcccccc}
\hline \multirow{2}{*}{ Scale } & \multirow{2}{*}{ Item } & \multirow{2}{*}{ Total scores } & Mean & \multicolumn{3}{c}{ Degree of diabetes distress } \\
& & & scores & Little or No & Moderate & High \\
\hline DDS17 & 17 & $34.6 \pm 12.6$ & 2.04 & $76(45.5)$ & $52(31.1)$ & $39(23.3)$ \\
Emotional burden & 5 & $12.5 \pm 5.7$ & 2.50 & $105(62.9)$ & $35(21.0)$ & $27(16.2)$ \\
Physician-related distress & 4 & $5.8 \pm 4.2$ & 1.45 & $126(75.4)$ & $26(15.6)$ & $15(9)$ \\
Regimen-related distress & 5 & $11.4 \pm 5.3$ & 2.28 & $137(82.0)$ & $12(7.2)$ & $18(10.8)$ \\
Diabetes-related interpersonal distress & 3 & $4.3 \pm 2.9$ & 1.43 & $119(71.3)$ & $23(13.8)$ & $25(15)$ \\
\hline
\end{tabular}

The questionnaire adopted in this study was consisted of two parts: the personal information and the DDS17. The first part accounted for the patient's personal information (shown in Table 2), including gender, education level, marital status, diabetes course, weight, BMI, HbA1c, blood pressure indicators (SBP and DBP), blood lipids indicators (TG, TC, LDL-C and HDL-C), treatment regimen, diabetes education, diet control, sleep time, and physical exercise (e.g., $150 \mathrm{~min} /$ week of moderate intensity of physical exercise in the past month). The second part of the questionnaire evaluated the T2DM patients' DD scores by the DDS17, which was proposed by Polonsky et al. (2005). Since most patients investigated were not able to read English in this study, we translated the DDS17 into Chinese. For validating the Chinese version of the DDS17, we first invited twelve experts in endocrinology who were able to read English to check whether the translation was accurate. We then conducted pilot study on the validity and reliability of the Chinese DDS17 by investigating 68 T2DM patients. The pilot study showed that this Chinese DDS17 was validated and reliable, because the Cronbach's $\alpha$ and reliability coefficients were 0.902 and 0.813 respectively.

This study adopted the 6-point Likert Scale to measure the T2DM patients' DD on each item in the DDS17. For each item, "1" denoted for "no problem", and " 6 " denoted for "severe". The DDS17 was consisted of four subscales, including emotional burden (30 points), physician-related distress (24 points), regimen-related distress (30 points) and diabetes-related interpersonal distress (18 points). To evaluate the degree of every patient's DD, we adopted the study of Fisher et al. (2012) in which an average DD score of 2.0 was set as the cut-off point. If the average DD score was lower than 2.0 (excluding 2.0), then the patient suffered no or little degree of distress. If the average DD score was between 2.0 and 3.0 (including 2.0 and excluding 
3.0), then the patient suffered moderate degree of DD. If the average DD score was above 3.0 (including 3.0), then the patient suffered high degree of DD.

Table 3 presented the statistical description of the DD scores for 167 T2DM patients. In this study, 52 and 39 T2DM patients suffered moderate and high degree of DD respectively. These two groups together took up $54.5 \%$ of the total patients investigated in our study. We found that it would be much easier for the T2DM patients in small-mid-sized city with less advanced medical conditions to suffer the DD than those in the regions with higher levels of medical treatment.

\section{RESULTS}

\section{Spearman correlation analysis for single influencing factor}

First, the Spearman correlation analysis was adopted to examine the impact of single factor on the T2DM patients' DD. The patients' DD scores were served as the dependent variables, while the independent variables were restricted to 16 influencing factors mentioned in Table 1, 2 and 3, which were: treatment regimen, physical excise, exercise time, diabetes education times, diet control, diabetes course, weight, BMI, HbAlc, sleep time, TG, TC, HDL-C, LDL-C, SBP and DBP. However, some factors, such as the gender, age and marital status, were excluded in this study. There were two reasons: (1) these factors had been well studied in Delahanty et al. (2007), and (2) the conclusions were similar to those given by Delahanty et al. (2007).
Table 4 presented the Spearman correlation coefficients and the respective significant levels of each influencing factor that affected the T2DM patients' DD. There were six significant influencing factors for DD: sleep time, exercise time, diet control, treatment regimen, TG and $\mathrm{HbAlc}$. Among these six influencing factors, sleep time had the highest correlation coefficient and most significantly affected the patients' $\mathrm{DD}(\mathrm{r}=-0.178, \mathrm{P}=0.002)$. Treatment regimen $(\mathrm{r}=0.164$, $\mathrm{P}=0.005)$ was the second most significant influencing factor, followed by the TG $(\mathrm{r}=-0.14, \mathrm{P}=0.005)$ and HbAlc $(r=0.122, \mathrm{P}=0.005)$. Similar to the findings in Graue et al. (2012), Strandberg et al. (2015) and Hessler et al. (2014), we also found that treatment regimen positively correlated with the T2DM patients' DD. However, we had another new finding: for the T2DM patients from a small-mid-sized city in China with lower level of medical conditions, sleep time was the most significant influencing factor that negatively influenced their DD.

To further explore how sleep time affected the patients' DD, the statistical diagram of the average DDS score regarding the sleep time intervals was shown in Figure 1. In this study, the sleep time was the summation of the sleep time during both day and night. The relationship between the total sleep time and the average DDS score presented to be U-curved in Figure 1. The patients who slept inadequately $(<4 \mathrm{~h})$ or excessively $(>10 \mathrm{~h})$ suffered the highest degree of DD, while those who slept 7 to 8 hours per day suffered the mildest degree of DD.

Table 4. Spearman correlation analysis between diabetes-related distress and its factors (r)

\begin{tabular}{|c|c|c|c|c|c|c|c|c|c|c|c|c|}
\hline \multirow[t]{2}{*}{ Scale } & \multicolumn{2}{|c|}{$\begin{array}{l}\text { Treatment } \\
\text { regimen }\end{array}$} & \multicolumn{2}{|c|}{$\begin{array}{l}\text { Physical } \\
\text { exercise }\end{array}$} & \multicolumn{3}{|c|}{ Exercise time } & \multicolumn{3}{|c|}{$\begin{array}{l}\text { Diabetes Edu. } \\
\text { Times }\end{array}$} & \multicolumn{2}{|c|}{ Diet Control } \\
\hline & $\mathrm{r}$ & $\mathrm{P}$ & $\mathrm{r}$ & $\mathrm{P}$ & & $\mathrm{r}$ & $\mathrm{P}$ & $\mathrm{r}$ & I & & $\mathrm{r}$ & $\mathrm{P}$ \\
\hline DDS17 & 0.164 & 0.005 & -0.146 & 0.066 & & .128 & 0.001 & 0.135 & 0.4 & $132-$ & -0.149 & 0.006 \\
\hline Emotional burden & 0.050 & 0.865 & 0.028 & 0.815 & & .155 & 0.001 & 0.335 & 0.0 & 51 & 0.023 & 0.72 \\
\hline Physician-related distress & 0.071 & 0.117 & 0.058 & 0.747 & & .153 & 0.529 & 0.037 & 0.8 & $302-$ & -0.101 & 0.092 \\
\hline Regimen-related distress & 0.113 & 0.018 & -0.17 & 0.045 & & .111 & 0.104 & 0.094 & 0.5 & $576-$ & -0.142 & 0.002 \\
\hline $\begin{array}{l}\text { Diabetes-related } \\
\text { interpersonal distress }\end{array}$ & 0.072 & 0.097 & -0.063 & 0.119 & & .056 & 0.826 & -0.046 & $\begin{array}{ll}5 & 0.8\end{array}$ & 342 & 0.011 & 0.865 \\
\hline \multirow{2}{*}{ Scale } & \multicolumn{2}{|c|}{ Diabetes Course } & \multicolumn{2}{|c|}{ Weight } & \multicolumn{3}{|c|}{ BMI } & \multicolumn{3}{|c|}{$\mathrm{HbA} 1 \mathrm{c}$} & \multicolumn{2}{|c|}{ Sleep Time } \\
\hline & $\mathrm{r}$ & $\mathrm{P}$ & $\mathrm{r}$ & $\mathrm{P}$ & & $\mathrm{r}$ & $\mathrm{P}$ & $\mathrm{r}$ & $\mathrm{I}$ & ? & $\mathrm{r}$ & $\mathrm{P}$ \\
\hline$\overline{\mathrm{DDS}}$ & 0.028 & 0.317 & -0.013 & 0.308 & & .12 & 0.084 & 0.122 & 0.0 & $05-$ & -0.178 & 0.002 \\
\hline Emotional burden & 0.051 & 0.459 & -0.144 & -0.004 & & .182 & 0.021 & 0.043 & 0.4 & $161-$ & -0.185 & 0.001 \\
\hline Physician-related distress & -0.036 & 0.812 & 0.022 & 0.511 & & .048 & 0.679 & 0.065 & 0.0 & $66-$ & -0.052 & 0.001 \\
\hline distress & 0.167 & 0.038 & -0.042 & 0.551 & & .04 & 0.516 & 0.103 & 0.0 & $14-$ & -0.097 & 0.002 \\
\hline $\begin{array}{l}\text { Diabetes-related } \\
\text { interpersonal distress }\end{array}$ & -0.079 & 0.539 & -0.059 & 0.566 & & .027 & 0.238 & 0.052 & 0.7 & $775-$ & -0.082 & 0.001 \\
\hline \multirow{2}{*}{ Scale } & \multicolumn{2}{|c|}{ TG } & \multicolumn{2}{|c|}{ TC } & \multicolumn{2}{|c|}{ HDL-C } & \multicolumn{2}{|c|}{ LDL-C } & \multicolumn{2}{|c|}{ SBP } & \multicolumn{2}{|c|}{ DBP } \\
\hline & $\mathrm{r}$ & $\mathrm{P}$ & $\mathrm{r}$ & $\mathrm{P}$ & $\mathrm{r}$ & $\mathrm{P}$ & $\mathrm{r}$ & $\mathrm{P}$ & $\mathrm{r}$ & $\mathrm{P}$ & $\mathrm{r}$ & $\mathrm{P}$ \\
\hline$\overline{\mathrm{DDS}}$ & -0.14 & 0.005 & 0.03 & 0.64 & 0.07 & 0.59 & -0.05 & $0.58 \quad($ & 0.06 & 0.90 & -0.14 & 0.71 \\
\hline Emotic & -0.05 & 0.005 & 0.01 & 0.55 & 0.05 & 0.13 & -0.09 & 0.21 & 0.01 & 0.01 & $1-0.06$ & 0.27 \\
\hline Physic & -0.05 & 0.005 & 0.02 & 0.46 & -0.06 & 0.58 & 0.04 & 0.67 & 0.14 & 0.06 & $\begin{array}{ll}5 & 0.07\end{array}$ & 0.75 \\
\hline distress & -0.14 & 0.005 & 0.06 & 0.69 & 0.07 & 0.82 & -0.04 & 0.52 & 0.03 & 0.61 & $1-0.05$ & 0.78 \\
\hline $\begin{array}{l}\text { Diabetes-related } \\
\text { interpersonal distress }\end{array}$ & -0.01 & 0.005 & -0.01 & 0.45 & 0.05 & 0.80 & 0.00 & 0.31 & 0.06 & 0.40 & -0.01 & 0.80 \\
\hline
\end{tabular}




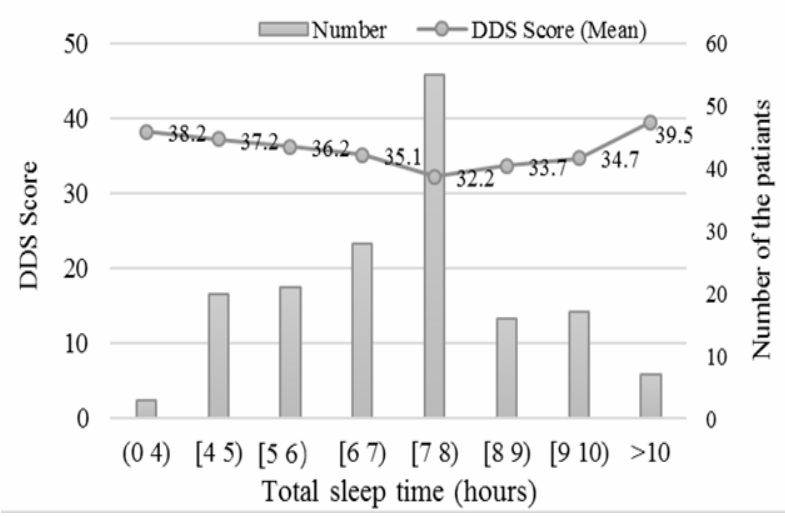

Figure 1. The relationship between the total sleep time and the average DDS score

Shown by Table 4, although the treatment regimen of the ciy investigated was not highly-advanced, it still ranked the second most significant influencing factor for the T2DM patients' DD. Table 5 illustrated the T2DM patients' DD under four different kinds of treatment regimens (e.g., Non-hypoglycemic agents, Oral hypoglycemic agents, Insulin and Oral+Insulin). The T2DM patients taking Non-hypoglycemic agents suffered the mildest degree of DD, while those taking both Oral hypoglycemic agents and Insulin suffered the highest degree of DD. However, all four kinds of treatment regimens showed little statistical significance on the subscale of emotional burden for the given significant level of 0.05 .

\section{Multivariate linear regression analysis for multiple influencing factors}

In the multivariate linear regression analysis, the DDS17 score was regarded as the dependent variable and other six influencing factors (e.g., sleep time, exercise time, diet control, treatment regimen, TG and HbAlc) were the independent variables. Second, DD score in the emotional burden subscale was regarded as the dependent variable, and then the stepwise multivariate linear regression analysis was conducted on five influencing factors (e.g., weight, BMI, sleep time, diabetes education times and exercise time) which were the independent variables. Third, the DD score in the Regimen-related distress subscale was regarded as the dependent variable, and then the stepwise multivariate linear regression analysis was conducted on six influencing factors (e.g., diabetes course, sleep time, physical exercise, diet control, treatment regimen and HbA1c) which were the independent variables. The significant level for a variable to enter the regression model was $\alpha=0.05$, while the significant level for a variables to be excluded was $\alpha=0.10$. The intergroup differences were examined by the t- test.

Table 6 presented the results of the multivariate linear regression analysis on DDS17, Emotional burden and Regimen-related distress subscales. For the DDS17, only the sleep time $(\beta=-0.213, P=0.034)$ entered the regression model, and accounted for $10.6 \%$ of the total variance. For the emotional burden subscale, the sleep time $(\beta=-0.379, \mathrm{P}=0.027)$ remained to be the only one that entered the regression model, and accounted for $30.7 \%$ of the total variance. For the subscale of regimen-related distress, three factors entering the regression model included physical exercise $(\beta=-0.195$, $\mathrm{P}=0.002)$, treatment regimen $(\beta=0.158, \mathrm{P}=0.026)$ and diet control $(\beta=-0.187, \mathrm{P}=0.009)$, which together accounted for $16.7 \%$ of the total variance. According to the Table 6 , the T2DM patients who took physical exercise and diet control suffered lower degree of DD, while those who adopted more complicated treatment regimen suffered higher degree of DD.

Table 5. The relationship between treatment regimen and DD

\begin{tabular}{lccccc}
\hline Scale & $\begin{array}{c}\text { Non-hypoglycemic } \\
\text { agents }\end{array}$ & $\begin{array}{c}\text { Oral hypoglycemic } \\
\text { agents }\end{array}$ & Insulin & Oral + Insulin & P \\
\hline DDS17 & $29.2 \pm 10.32$ & $34.4 \pm 13.34$ & $36.2 \pm 17.33$ & $38.1 \pm 18.30$ & 0.047 \\
Emotional burden & $9.5 \pm 8.32$ & $10.34 \pm 8.87$ & $12.08 \pm 9.01$ & $12.87 \pm 8.71$ & 0.281 \\
Physician-related distress & $4.82 \pm 2.45$ & $5.93 \pm 2.66$ & $6.24 \pm 3.51$ & $6.51 \pm 4.72$ & 0.006 \\
Regimen-related distress & $10.38 \pm 4.46$ & $12.4 \pm 4.88$ & $11.29 \pm 5.40$ & $12.01 \pm 5.87$ & 0.016 \\
Diabetes-related & $4.5 \pm 1.78$ & $5.73 \pm 2.03$ & $6.59 \pm 2.36$ & $6.71 \pm 3.06$ & 0.013 \\
interpersonal distress & & & & & \\
\hline
\end{tabular}

Table 6. Multivariate linear regression for DDS17, emotional burden and regimen-related distress

\begin{tabular}{llrrr}
\hline Dependent variable & Independent variable & \multicolumn{1}{c}{$\mathrm{t}$} & $\mathrm{P}$ \\
\hline DDS17 & Constant & 44.175 & 6.892 & 0.000 \\
& Sleep Time & -0.213 & -2.654 & 0.034 \\
Emotional burden & Constant & 32.719 & 4.420 & 0.000 \\
& Sleep Time & -0.379 & -2.119 & 0.027 \\
Regimen-related distress & Constant & 15.821 & 8.263 & 0.000 \\
& Physical Exercise & -0.195 & -2.825 & 0.002 \\
& Treatment Regimen & 0.158 & 2.562 & 0.026 \\
& Diet Control & -0.187 & -2.674 & 0.009 \\
\hline
\end{tabular}




\section{DISCUSSION}

This study prompted five insights shown as below. These insights were of significant importance for the medical staff who should advise their T2DM patients in the regions where the medical conditions were at low level.

First, sleep time, physical exercise and diet control ranked the top three of the most significant influencing factors for the T2DM patients' DD in the undeveloped small-mid-sized city (e.g., Jinhua city as mentioned) where medical conditions and treatment regimen qualities were not advanced. This finding was different from the studies of Strandberg et al. (2015) and Hessler et al. (2014), in which treatment regimen, TG and HbAlc were the most influencing factors for the patients in developed regions with medical conditions and qualities at high levels. Based on the differences, we suggested that the medical staff in undeveloped regions should advise the T2DM patients to keep healthier daily life for alleviating their DD.

Second, sleep time was the most significant influencing factor for the T2DM patients' DD. Either inadequate or excessive sleep would increase the patients' DD. The T2DM patients who slept less than 6 hours or more than 8 (or 9) hours might more easily trigger the Diabetes. This finding was consistent with those of Cappuccio et al. (2010) and Ip \& Mokhlesi (2007). Sleep disorder could confound the T2DM patients' glycemic control and further increase their negative emotions which could further damage their sleep qualities. In this sense, negative emotions and poor sleep qualities together created a vicious circle that worsened DD in patients. Therefore, for the T2DM patients with inadequate sleep, extending the sleep time might help alleviate DD. However, for the patients with regular sleep, excessive sleep time might have the opposite effect. Based on this finding, we strongly suggested that (1) to help the patients with inadequate sleep, the medical staff could prescribe placebos to prolong their sleep time, and (2) to help patients with excessive sleep, the medical staff could intervene to shorten the T2DM patients' sleep time (e.g., setting an alarm to wake them up).

Third, the T2DM patients who did physical exercise and kept regular regimen suffered lower degrees of DD. Because doing physical exercise not only helped the patients control their weights, but also improved their interpersonal relations and won the social supports, thus contributing a lot to improving their life qualities. Based on these findings, we suggested the T2DM patients should participate more in collective or communal physical activities to increase the frequencies of interaction with others in communitiy.

Fourth, our study provided further evidence for the finding of Makine et al. (2009). Like the T2DM patients in the developed regions, patients in the undeveloped regions would also suffer higher degree of regimen- related distress when they adopt more complicated treatment regimen. The T2DM patients who adopted the insulin therapies could suffer higher degree of DD than those who resorted to oral hypoglycemic agents and the diet therapies. Therefore, in order to reduce patients' fear and their misunderstanding of the insulin therapies, we suggested the medical staff should patiently explain the positive effects of insulin and oral+insulin therapies to the T2DM patients.

Last but not least, diet control and diet planning could alleviate regimen-related distress. This finding was similar to the ones discovered by Karlsen et al. (2012) and Baek et al. (2014). Considering diet control as a kind of social supports, we suggested that medical staff should plan the diet with the patients to help them improve self-management and self-control.

\section{CONCLUSION}

In this study, 167 adult T2DM patients were selected from an A-grade hospital of a small-mid-sized city (i.e., Jinhua) in Eastern China with the aim of exploring the influencing factors for their DD. All T2DM patients were from the undeveloped regions where the medical conditions and treatment regimens for DM were not highly advanced. Sleep time, physical exercise, diet control, treatment regimen, TG and $\mathrm{HbAlc}$ were the six most significant influencing factors that had an impact on the patients' DD. Particularly, sleep time was the top influencing factor that significantly had an impact on the T2DM patients' DD (especially on the emotional burden related DD). Besides, physical exercise, treatment regimen and diet control were the other three influencing factors which significantly had an impact on the patients' regimen-related distress. Based on the findings in this study, there are four suggestions for the medical staff who must advise the T2DM patients in the regions with low-level medical conditions and treatment regimens. (1) Improving the patients' sleep qualities could alleviate their degrees of DD. (2) Doing physical exercise with the community could win the social supports and reduce their DD. (3) Correcting the patients' misunderstanding of insulin treatment could reduce their fear and improve the effect of treatment. (4) Helping patients with diet control and diet planning could improve their self-management.

\section{Acknowledgements: None.}

\section{Conflict of interest: None to declare.}

\section{Contribution of individual authors:}

All authors made a substantial contribution to the design of the study, and/or data acquisition, and/or the data analysis and its interpretation. 


\section{References}

1. Baek RN, Tanenbaum ML, Gonzalez JS: Diabetes Burden and Diabetes Distress: the Buffering Effect of Social Support. Ann Behav Med 2014; 48:145-55

2. Cappuccio FP, Delia L, Strazzullo P, et al: Quantity and Quality of Sleep and Incidence of Type 2 Diabetes $A$ systematic review and meta-analysis. Diabetes Care 2010; 33:414-20

3. De Vries L, Der Heijden AAWAV, Riet EVT, et al: Peer support to decrease diabetes-related distress in patients with type 2 diabetes mellitus: design of a randomised controlled trial. BMC Endocr Disord 2014; 14:21-6

4. Delahanty LM, Grant RW, Wittenberg E, et al: Association of diabetes $\square$ related emotional distress with diabetes treatment in primary care patients with Type 2 diabetes. Diabetic Med 2007; 24:48-54

5. Fisher L, Hessler D, Polonsky WH, et al: When Is Diabetes Distress Clinically Meaningful? Establishing cut points for the Diabetes Distress Scale. Diabetes Care 2012; 35:259-64

6. Graue M, Haugstvedt A, Wentzellarsen T, et al: Diabetesrelated emotional distress in adults: reliability and validity of the Norwegian versions of the Problem Areas in Diabetes Scale (PAID) and the Diabetes Distress Scale (DDS). Int J Nurs Stud 2012; 49:174-82

7. Hessler D, Fisher L, Glasgow RE, et al: Reductions in Regimen Distress Are Associated With Improved Management and Glycemic Control Over Time. Diabetes Care 2014; 37:617-24

8. Ikeda K, Fujimoto S, Morling B, et al: Social Orientation and Diabetes-Related Distress in Japanese and American Patients with Type 2 Diabetes. PLOS One 2014; 9

9. Ip M, Mokhlesi B: Sleep and Glucose Intolerancel Diabetes Mellitus. Sleep Med Clinics 2007; 2:19-29

10. Jones A, Olsen MZ, Perrild HJD, et al: The psychological impact of living with diabetes: Descriptive findings from the DAWN2 study in Denmark. Prim Care Diabetes 2016; 10:83-6

11. Karlsen B, Oftedal B, Bru E: The relationship between clinical indicators, coping styles, perceived support and diabetes-related distress among adults with type 2 diabetes. J Adv Nurs 2012; 68:391-401
12. Kasteleyn MJ, De Vries L, Van Puffelen AL, et al: Diabetes-related distress over the course of illness : results from the Diacourse study. Diabetic Med 2015; 32:1617-24

13. Li C, Barker LE, Ford ES, et al: Diabetes and anxiety in US adults: findings from the 2006 Behavioral Risk Factor Surveillance System. Diabetic Med 2008; 25:878-81

14. Makine C, Karsidag C, Kadioglu P, et al: Symptoms of depression and diabetes-specific emotional distress are associated with a negative appraisal of insulin therapy in insulin-naïve patients with Type 2 diabetes mellitus. A study from the European Depression in Diabetes [EDID] Research Consortium. Diabetic Med 2009; 26:28-33

15. Nouwen A: Depression and diabetes distress. Diabetic Med 2015; 32:1261-1263

16. Polonsky WH, Anderson BJ, Lohrer PA, et al: Assessment of diabetes-related distress. Diabetes Care 1995; 18:754-60

17. Polonsky WH, Fisher L, Earles J, et al: Assessing Psychosocial Distress in Diabetes: Development of the Diabetes Distress Scale. Diabetes Care 2005; 28:626-31

18. Reddy J, Wilhelm $K$ and Campbell L: Putting PAID to Diabetes-Related Distress: The Potential Utility of the Problem Areas in Diabetes (PAID) Scale in Patients with Diabetes. Psychosomatics 2013; 54:44-51

19. Snoek FJ, Kersch NYA, Eldrup E, et al: Monitoring of Individual Needs in Diabetes (MIND): Baseline Data From the Cross-National Diabetes Attitudes, Wishes, and Needs (DAWN) MIND Study. Diabetes Care 2011; 34:601-3

20. Strandberg RB, Graue M, Wentzellarsen T, et al: Longitudinal relationship between diabetes-specific emotional distress and follow-up HbAlc in adults with Type 1 diabetes mellitus. Diabetic Med 2015; 32:1304-10

21. Thorne SE, Paterson BL: Health care professional support for self-care management in chronic illness: insights from diabetes research. Patient Educ Couns 2001; 42:81-90

22. Wagner J, Tennen H: History of major depressive disorder and diabetes outcomes in diet- and tablet-treated post-menopausal women: a case control study. Diabetic Med 2007; 24:211-6

23. Wardian J, Sun F: Factors Associated With DiabetesRelated Distress: Implications for Diabetes Self-Management. Soc Work Health Care 2014; 53:364-81

Correspondence:

Huilan Bao, MD

The Endocrinology Department of the People's Hospital of Jinhua Jinhua, 321000, China

E-mail:huilanbao@outlook.com 